УДК 544.228

DOI https://doi.org/10.32782/pcsd-2021-2-3

\title{
Олег МАРЧУК
}

кандидат хімічних наук, доцент, доцент кафедри хімії та технологій, Волинський національний університет імені Лесі Українки, просп. Волі, 13, м. Луцьк, Волинська обл., Украӥна, 43025

ORCID: 0000-0002-5618-7156

\section{Олександр СМІТЮХ}

кандидат хімічних наук, стариий лаборант кафедри хімії та технологій, Волинський національний університет імені Лесі Украӥнки, просп. Волі, 13, м. Луцьк, Волинська обл., Украйна, 43025

ORCID: 0000-0003-1632-5849

Бібліографічний опис статті: Марчук, О., Смітюх, О. (2021). Нецентросиметрична структура селенідів $\mathrm{M}_{3} \mathrm{Si}_{1.75} \mathrm{Se}_{7}(\mathrm{M}=0.5 \mathrm{Y}+0.5 \mathrm{La}(\mathrm{Pr}))$ Проблеми хімії та сталого розвитку, 2, 15-18, doi: https://doi.org/10.32782/pcsd-2021-2-3

\section{НЕЦЕНТРОСИМЕТРИЧНА СТРУКТУРА СЕЛЕНІДІВ $\mathrm{M}_{3} \mathrm{Si}_{1.75} \mathrm{Se}_{7}(\mathrm{M}=0.5 \mathrm{Y}+0.5 \mathrm{La}(\mathrm{Pr}))$}

\begin{abstract}
У статті вивчається проблематика кристалічної структури тетрарних халькогенідів $M_{3} \mathrm{Si}_{1.75} \mathrm{Se}_{7}(\mathrm{M}=0.5 \mathrm{Y}+0.5 \mathrm{La}(\mathrm{Pr}))$. Сполуки отримані методом твердофазних реакцій взаємодією елементарних компонентів за температури 1323 К. Зйомка дифрактограм порошкоподібних зразків проводилася за кімнатної температури на ДРОН-4-13.Кристалічна структура розрахована за допомогою пакету програм WINCSD (Bepciя 2016p.) i описується символом Пірсона һP23. Проблематика иих структур полягає не лише в локалізації суміші атомів рідкісноземельних елементів (РЗЕ), а й у появі атомів Силічію у двох зарядових станах $+2 i+4$, щзо не вивчалося раніме в наукових роботах. Такий підхід дозволяє більш глибше вивчити кристалічну структуру отриманих фаз на предмет взаємозв'язку між зарядом атома і його координаційним оточенням. Згідно з багатьма дослідженнями, локалізація атомів, щуо несуть протилежний заряд відносно иеентрального координаційного атома визначається положенням атома в ПС і його зарядом. У більшості досліджень спостерігається варіант опису структури, коли до складу входять йони, щзо мають певний сталий умовний заряд + або -. У иій роботі запропонований розв'язок структури, в якій Силічій із зарядом 2+ локалізований в ПСТ 2a, а Силіиій з зарядом +4 - в ПСТ 2b. Окрім того, ие призводить $і$ до різного координаційного оточення ичи атомів (КЧ $=6$ i 4 відповідно). Структуру проаналізовано не предмет утворення катіон-катіоних пар між атомами Силіцію, як найбільш електронегативного атому. Проведена порівняльна оцінка з відомими дослідженнями, щз відображають подібну проблематику $і$ встановлено, щзо такі пари в цій структурі неможливі через значні міжатомні віддалі Si-Si, щзо призводить до руйнування такої геометричної конфігурачії. Атоми Силічію, щзо перебувають в тетраедричному оточенні атомами Селену мають порівняно короткі міжатомні віддалі Si-Se, щз свідчить про їх переважно ковалентну природу. В октаедричному оточенні атоми Силіцію мають значно більші значення, що вказує на збільшення йонності зв 'язку.
\end{abstract}

Ключові слова: кристалічна структура, координачійне оточення, правильна система точок, центральний атом.

\section{Oleg MARCHUK}

PhD in Chemistry, Associate Professor, Senior Lecturer at the Department of Chemistry and Technology, Lesya Ukrainka Volyn National University, 13 Voli ave., Lutsk, Volyn region, Ukraine, 43025

ORCID: 0000-0002-5618-7156

\section{Oleksandr SMITIUKH}

PhD in Chemistry, Senior Assistant at the Department of Chemistry and Technology, Lesya Ukrainka Volyn National University, 13 Voli ave., Lutsk, Volyn region, Ukraine, 43025

ORCID: 0000-0003-1632-5849

To cite this article: Marchuk, O. \& Smitiukh, O. (2021). Netsentrosymetrychna struktura selenidiv $\mathrm{M}_{3} \mathrm{Si}_{1.75} \mathrm{Se}_{7}(\mathrm{M}=0.5 \mathrm{Y}+0.5 \mathrm{La}(\mathrm{Pr}))$ [Noncentrosymmetric crystal structure of selenides $\left.\mathrm{M}_{3} \mathrm{Si}_{1.75} \mathrm{Se}_{7}(\mathrm{~m}=0.5 \mathrm{Y}+0.5 \mathrm{La}(\mathrm{Pr}))\right]$. Problems of Chemistry and Sustainable Development, 2, 15-18, doi: https://doi.org/10.32782/pcsd-2021-2-3 


\section{NONCENTROSYMMETRIC CRYSTAL STRUCTURE OF SELENIDES $\mathrm{M}_{3} \mathrm{Si}_{1.75} \mathrm{Se}_{7}(\mathrm{M}=0.5 \mathrm{Y}+0.5 \mathrm{La}(\mathrm{Pr}))$}

The article studies the problems of the crystal structure of tetrar chalcogenides $M_{3} \mathrm{Si}_{175} \mathrm{Se}_{7}(\mathrm{M}=0.5 \mathrm{Y}+0.5 \mathrm{La}(\mathrm{Pr}))$. The compounds were obtained by the method of solid-phase reactions by the interaction of elementary components at a temperature of $1323 \mathrm{~K}$. The diffraction patterns of powder samples were taken at room temperature on DRON-4-13. The problem of these structures is not only the localization of a mixture of atoms of rare earth elements (REE), but also the appearance of silicon atoms in two charge states +2 and +4 , which has not been previously studied in scientific papers. This approach allows a deeper study of the crystal structure of the obtained phases for the relationship between the charge of the atom and its coordination environment. According to many studies, the localization of atoms carrying the opposite charge relative to the central coordination atom is determined by the position of the atom in the periodic system and its charge. In most studies, there is a variant of the description of the structure, when the composition includes ions with a certain constant conditional charge + or -. In this paper, we propose a solution of the structure in which Silicon with charge $2+$ is localized in a site $2 a$, and Silicon with charge +4 is localized in a site $2 b$. In addition, this leads to a different coordination environment of these atoms (C.N. $=6$ and 4, respectively)

The structure was analyzed by the formation of cation-cation pairs between silicon atoms, as the most electronegative atom. A comparative evaluation with known studies that reflect similar issues and found that such pairs in this structure are impossible due to the significant interatomic distances of Si-Si, which leads to the destruction of such a geometric configuration. Silicon atoms in a tetrahedral environment with selenium atoms have relatively short interatomic Si-Se distances, which indicates their predominantly covalent nature. In an octahedral environment, silicon atoms are much larger, indicating an increase in the ionicity of the bond.

Key words: crystalline structure, coordinate setting, site of atom, central atom.

Отримання нових матеріалів для сучасної техніки - це не просто вимога часу, а й технологічно обгрунтоване рішення, що базується на аналізі проблематики існуючих матеріалів. Вдосконалення технологій водночасі підвищує вимоги щодо властивостей використовуваних матеріалів.

Науковий пошук сьогодення спрямований на прогнозований підхід щодо відбору речових. Інакше кажучи, задача полягає в утриманні речовин 3 наперед заданими властивостями. Неабиякий інтерес $\epsilon$ до напівпровідникових властивостей халькогенідів рідкісноземельних металів. Це обумовлюється тим, що ці елементи утворюють досить цікаве різноманіття структур, що кристалізуються в нецентросиметричних групах. А це в свою чергу відкриває ще один напрямок використання їх як оптичних елементів [1], [2].

Звісно, що базис для досліджень уже сформований багаторічними напрацюваннями кафедри хімії та технологій і ця робота є лише продовженням реалізації планових експериментів у вивченні поведінки хімічних елементів у квазіпотрійних системах $\mathrm{D}^{\mathrm{IV}} \mathrm{X}_{2}-\mathrm{R}_{2} \mathrm{X}_{3}-\mathrm{R}_{2}^{\prime} \mathrm{X}_{3}\left(\mathrm{D}^{\mathrm{IV}}-\mathrm{Si}\right.$, Ge, Sn; R, R' - P3M; X - S, Se) [3], [4] і ін.).

Наважки зразків для дослідження були підготовлені з високочистих компонентів у кварцевих ампулах. Синтез сплавів проводили у вакуумованих контейнерах в електричній муфельній печі з програмним управлінням технологічними процесами МП-30 згідно наступного режиму: нагрів до температури $1150^{\circ} \mathrm{C}$ із швидкістю $12^{\circ} \mathrm{C} /$ год; витримка за температури $1150^{\circ} \mathrm{C}$ протягом 4 годин; охолодження за температури $500{ }^{\circ} \mathrm{C}$ із швидкістю $12^{\circ} \mathrm{C} /$ год; гомогенізуючий відпал за температури $500^{\circ} \mathrm{C}$ протягом 500 годин; гартування у холодну воду.

Рентгенівські порошкограми отримували на дифрактометрі DRON-4-13 (CuK $\alpha$ - випромінення, $10^{\circ} \leq 2 \theta \leq 100^{\circ}$, крок зйомки $0.05^{\circ}$, експозиція у кожній точці 20 с) і рахували їх за допомогою пакету програм WINCSD [5]. Дифрактограми порошків представлено на рис. 1-2.

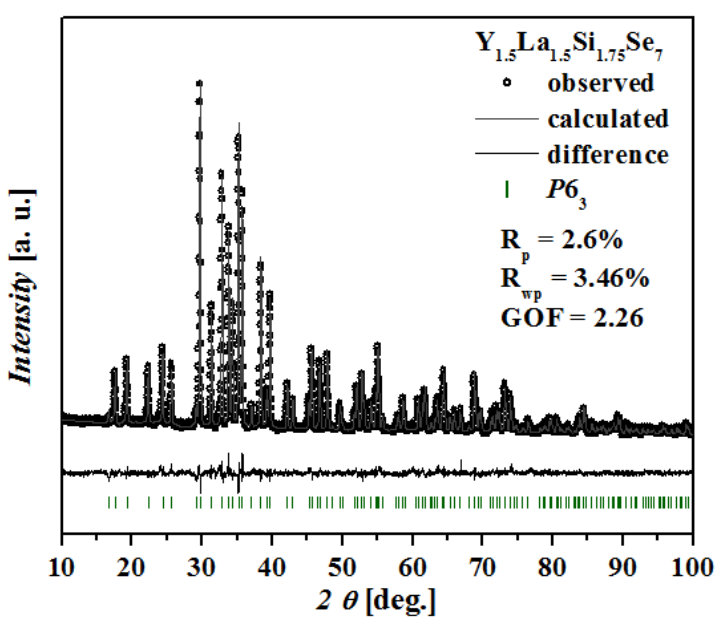

Рис. 1. Дифрактограма структури $\mathrm{M}_{3} \mathrm{Si}_{1.75} \mathrm{Se}_{7}(\mathrm{M}-(0.5 \mathrm{Y}+0.5 \mathrm{La})$

Кристалічна структура 3 символом Пірсона $h P 23$ вказує на те, що в ній реалізується 
примітивна комірка 3 параметрами гексагональної сингонії та кількістю атомів, що припадають на одну комірку, рівною 23. У цій групі $\epsilon$ три типи позицій $-2 a, 2 b$ і $6 c$.

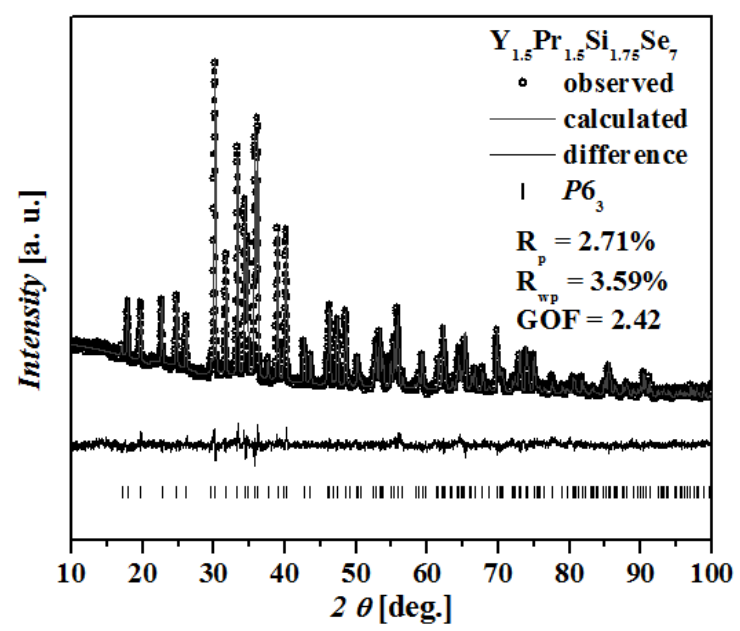

Рис. 2. Дифрактограма структури $\mathrm{M}_{3} \mathrm{Si}_{1.75} \mathrm{Se}_{7}(\mathrm{M}-(0.5 \mathrm{Y}+0.5 \mathrm{Pr})$

$\mathrm{y}$ вузлах комірки локалізовані атоми $\mathrm{Si}$ 3 октаедричним оточенням атомами Se. Позиція, що знаходиться на 1/3 від вихідного положення в напрямку $x$ заповнена атомами $\mathrm{Si}$ на 0.75 частки, що відповідає просторовому заповненню цієї групи, і оточена 4 атомами Se, що утворюють тетраедр навколо центального атома Si. Найважчі атоми займають позицію $6 c$. На рис. 3 проілюстровано проекцію елементарної комірки на площину $b c$.

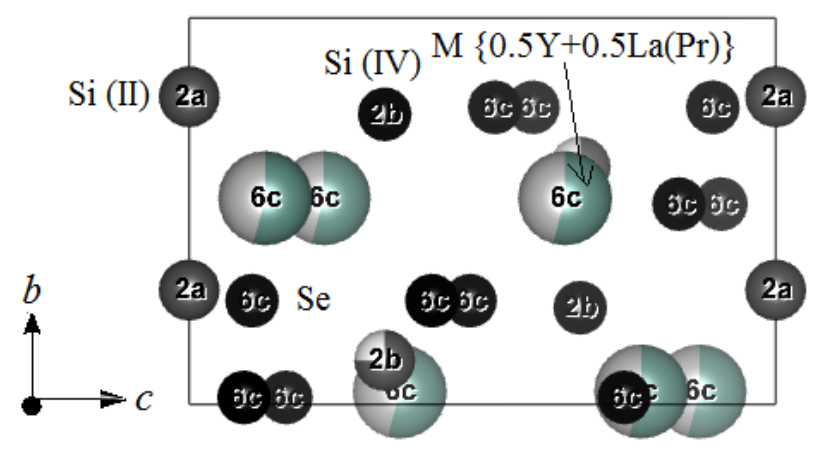

Рис. 3. Проекція елементарної комірки на площину $b c$

Оскільки природа атомів є споріднена, то вони можуть утворювати статистичну суміш, що й реалізовано в цій структурі. Говорячи про величини довжин зв' язку у такій системі, зазначатимо їх як адитивні величини. Провівши розподіл атомних позицій, з'ясовуємо що кінцева формула, якщо брати до уваги $\mathrm{Si}$ з зарядом +4 не відповідає принципу електронейтральності. Проводячи аналіз міжатомних відстаней, які можуть дати відповідь на питання щодо проценту йонності чи ковалентності зв'язку, а також який умовний заряд зосереджений на атомі, стає зрозуміло, що в центрі октаедрів

Таблиця 1

Атомні координати та ізотропні параметри структури $\mathrm{M}_{3} \mathrm{Si}_{175} \mathrm{Se}_{7}(\mathrm{M}-0.5 \mathrm{Y}+0.5 \mathrm{La})$

\begin{tabular}{|c|c|c|c|c|c|c|}
\hline Атоми & $\boldsymbol{x} / \boldsymbol{a}$ & $\boldsymbol{y} / \boldsymbol{b}$ & $\boldsymbol{z} / \boldsymbol{c}$ & $\mathbf{U}(\mathbf{e q})$ & $\mathbf{N}$ & Зайнятість \\
\hline $\mathrm{M}$ & $0.1296(1)$ & $0.3591(1)$ & $0.0357(4)$ & $1.47(5)$ & 6 & $0.5 \mathrm{Y}+0.5 \mathrm{La}$ \\
\hline $\mathrm{Se} 1$ & $0.2573(2)$ & $0.1645(2)$ & $0.0193(5)$ & $2.01(8)$ & 6 & 1.0 \\
\hline $\mathrm{Se} 2$ & $0.5215(2)$ & $0.1080(2)$ & $0.2714(4)$ & $1.40(7)$ & 6 & 1.0 \\
\hline $\mathrm{Se} 3$ & $1 / 3$ & $2 / 3$ & $0.2525(6)$ & $1.19(8)$ & 2 & 1.0 \\
\hline $\mathrm{Si} 1$ & $1 / 3$ & $2 / 3$ & $0.6182(15)$ & $1.8(3)$ & 2 & 0.75 \\
\hline $\mathrm{Si} 2$ & 0 & 0 & $-0.204(3)$ & $0.5(2)$ & 2 & 1.0 \\
\hline \multicolumn{7}{|c|}{$\mathrm{U}(\mathrm{eq})=4 / 3\left[\mathrm{U} 11 \mathrm{a}^{*} 2 \mathrm{a} 2+\ldots 2 \mathrm{U} 23 \mathrm{~b}^{*} \mathrm{c}^{*} \mathrm{~b} \mathrm{c} \cos (\alpha)\right]$} \\
\hline
\end{tabular}

Таблиця 2

Атомні координати та ізотропні параметри структури $\mathrm{M}_{3} \mathrm{Si}_{175} \mathrm{Se}_{7}(\mathrm{M}-0.5 \mathrm{Y}+0.5 \mathrm{Pr})$

\begin{tabular}{|c|c|c|c|c|c|c|}
\hline Атоми & $\boldsymbol{x} / \boldsymbol{a}$ & $\boldsymbol{y} / \boldsymbol{b}$ & $\boldsymbol{z} / \boldsymbol{c}$ & $\mathbf{U}(\mathbf{e q})$ & $\mathbf{N}$ & Зайнятість \\
\hline $\mathrm{M}$ & $0.1297(1)$ & $0.3591(1)$ & $0.0336(4)$ & $0.58(2)$ & 6 & $0.5 \mathrm{Y}+0.5 \mathrm{La}$ \\
\hline $\mathrm{Se} 1$ & $0.2583(2)$ & $0.1649(2)$ & $0.0183(5)$ & $1.17(4)$ & 6 & 1.0 \\
\hline $\mathrm{Se} 2$ & $0.5210(2)$ & $0.1072(2)$ & $0.2686(4)$ & $0.56(4)$ & 6 & 1.0 \\
\hline $\mathrm{Se} 3$ & $1 / 3$ & $2 / 3$ & $0.2505(6)$ & $0.72(7)$ & 2 & 1.0 \\
\hline $\mathrm{Si} 1$ & $1 / 3$ & $2 / 3$ & $0.614(2)$ & $0.3(4)$ & 2 & 0.75 \\
\hline $\mathrm{Si} 2$ & 0 & 0 & $-0.204(3)$ & $0.7(2)$ & 2 & 1.0 \\
\hline \multicolumn{7}{|c|}{$\mathrm{U}(\mathrm{eq})=4 / 3\left[\mathrm{U} 11 \mathrm{a}^{*} 2 \mathrm{a} 2+\ldots 2 \mathrm{U} 23 \mathrm{~b}^{*} \mathrm{c}^{*} \mathrm{~b} \mathrm{c} \cos (\alpha)\right]$} \\
\hline
\end{tabular}


перебувають атоми Силіцію 3 зарядом +2 , а в позиції $2 b-\mathrm{Si}(+4)$. Окрім того, перевіряємо гіпотезу існування катіон-катіонних пар. Якщо брати до уваги, що найбільш електронегативним серед катіонів є Силіцій, отже він має тенденцію до утворення катіон-катіонних пар. Згідно відомих наукових досліджень для Силіцію такий варіант може бути реалізованим за умови, якщо $\delta(\mathrm{Si}-\mathrm{Si}) \geq 0.280$ нм. Порахована відстань досліджуваних нами структур $є \delta(\mathrm{Si}-\mathrm{Si}) \geq 0.300$ нм, а отже такі пари не утворюються.
Таким чином, отримуємо картину кристалічної структури селенідів $\mathrm{M}_{3} \mathrm{Si}_{1.75} \mathrm{Se}_{7}$ $(\mathrm{M}-0.5 \mathrm{Y}+0.5 \mathrm{La}(\mathrm{Pr}))$, в якій структурні параметри сполук, аналіз міжатомних віддалей і найближчого координаційного оточення атомів вказують на те, що в їх складі Силіцій перебуває в двох валентних станах: +2 (в октаедрах) $\mathrm{i}+4$ (в тетраедрах). У тетраедрах атом Si утворює порівняно короткі, переважно ковалентні, зв'язки $\mathrm{Si}-\mathrm{Se}$, а в октаедрах зв'язки є більш довгі та істотно іонні.

\section{ЛІТЕРАТУРА:}

1. Daszkiewicz M., Pashynska Yu., Marchuk O., Gulay L. Crystal structure of $\mathrm{R}_{3} \mathrm{Co}_{0.5} \mathrm{GeS}_{7}(\mathrm{r}=$ rare earth). (Collected Abstracts of the $55^{\text {st }}$ Polish Crystallographic Meeting. Wroclaw (Poland). 27-29 June. 2013. A. 47.

2. Pashynska Yu.O., Daszkiewicz M., Marchuk O.V., Gulay L.D. Crystal structure of $\mathrm{Sm}_{3} \mathrm{Fe}_{0.5} \mathrm{SnS}_{7^{\prime}}$ Релаксаційні, нелінійні й акустооптичні процеси та матеріали: матеріали VII Міжнар. наук. конф. Луцьк : Вежа - Друк. 2014. C. 39-41.

3. Смітюх О.В., Харкевич Л.М., Марчук О.В., Олексеюк І.Д., Федорчук А.О. Кристалічна структура сполуки $\mathrm{Y}^{3+}{ }_{1.5} \mathrm{La}^{3+}{ }_{1.5} \mathrm{Si}^{4+}{ }_{0.75} \mathrm{Si}^{2+} \mathrm{Se}^{2-}{ }_{7}$. XII Всеукр. конф. мол. вч. та студ. 3 акт. питань хімії. Збірка праць. м. Харків: Ексклюзив. 2016. C. 58.

4. Смітюх О.В., Савчук Р.М., Марчук О.В. Олексеюк І.Д., Федорчук А.О. Кристалічна структура сполуки $\mathrm{Y}^{3+}{ }_{1.5} \mathrm{Pr}^{3+}{ }_{1.5} \mathrm{Si}^{4+}{ }_{0.75} \mathrm{Si}^{2+} \mathrm{Se}^{2-}{ }_{7}$. Збірник тез доповідей XVIII Наук. молод. конф. «Проблеми та досягнення сучасної хімії» (17-20 травня 2016 року, м. Одеса). м. Київ: ТОВ НВП “Інтерсервіс". 2016. С. 132.

5. L.G. Aksel'rud, Yu.N. Grin', P.Yu. Zavalii and others CSD - Universal program package for simgle crustal and powder structure data treatment. Collected Abstracts 12th European Crystallogr. Meet. Moscow: USSR. 20-28 August. 1989. Vol. 3. P. 155.

\section{REFERENCES:}

1. Daszkiewicz M., Pashynska Yu., Marchuk O., Gulay L. (2013). Crystal structure of $\mathrm{R}_{3} \mathrm{Co}_{0.5} \mathrm{GeS}_{7}(\mathrm{r}=$ rare earth). (Collected Abstracts of the 55t Polish Crystallographic Meeting. Wroclaw (Poland). 27-29 June. A. 47 [in English].

2. Pashynska, Yu.O., Daszkiewicz, M., Marchuk, O.V., Gulay, L.D. (2014). Crystal structure of $\mathrm{Sm}_{3} \mathrm{Fe}_{0.5} \mathrm{SnS}_{7}$. Relaksatsiini, neliniini y akustooptychni protsesy ta materialy: materialy VII Mizhnar. nauk. konf. [Relaxation, nonlinear and acousto-optical processes and materials: materials VII International. Science. Conf]. Lutsk : Vezha - Druk. S. 39-41 [in Ukrainian].

3. Smitiukh, O.V., Kharkevych, L.M., Marchuk, O.V., Olekseiuk, I.D., Fedorchuk, A.O. (2015) Krystalichna struktura spoluky $\mathrm{Y}^{3+}{ }_{1.5} \mathrm{La}^{3+}{ }_{1.5} \mathrm{Si}^{4+}{ }_{0.75} \mathrm{Si}^{2+} \mathrm{Se}^{2-}{ }_{7}$ KhII Vseukr. konf. mol. vch. ta stud. z akt. pytan khimii. Zbirka prats [Crystal structure of compound Y3 + 1.5La3 + 1.5Si4 + 0.75Si2 + Se2-7. XII All-Ukrainian conf. mol. incl. and stud. with act. chemistry issues. Collection of works]. Kharkiv: Ekskliuzyv, 58. [in Ukrainian].

4. Smitiukh, O.V., Savchuk, R.M., Marchuk, O.V., Olekseiuk, I.D., Fedorchuk, A.O. (2016). Krystalichna struktura spoluky $\mathrm{Y}_{1.5}^{3+}{ }_{1.5} \mathrm{Pr}_{1.5}^{3+} \mathrm{Si}^{4+}{ }_{0.75} \mathrm{Si}^{2+} \mathrm{Se}^{2-}$. Zbirnyk tez dopovidei XVIII Nauk. molod. konf. «Problemy ta dosiahnennia suchasnoi khimii» (17-20 travnia 2016 roku, m. Odesa). [Crystal structure of compound Y3 $+1.5 \mathrm{Pr} 3+1.5 \mathrm{Si} 4+0.75 \mathrm{Si} 2+$ Se2-7. Collection of abstracts of reports XVIII Sciences. young. conf. "Problems and achievements of modern chemistry" (May 17-20, 2016, Odessa)]. Kyiv: TOV NVP "Interservis". 132.[In Ukrainian].

5. Aksel'rud L.G., Grin Yu.N., Yu P. (1989). Zavalii and others CSD - Universal program package for simgle crustal and powder structure data treatment. Collected Abstracts 12th European Crystallogr. Meet. Moscow: USSR. 20-28 August. 3, 155 [in English]. 